\title{
Restoring Detroit's Street Lighting System
}

\section{September 2015}

Bruce Kinzey 


\title{
DISCLAIMER
}

This report was prepared as an account of work sponsored by an agency of the United States Government. Neither the United States Government nor any agency thereof, nor Battelle Memorial Institute, nor any of their employees, makes any warranty, express or implied, or assumes any legal liability or responsibility for the accuracy, completeness, or usefulness of any information, apparatus, product, or process disclosed, or represents that its use would not infringe privately owned rights. Reference herein to any specific commercial product, process, or service by trade name, trademark, manufacturer, or otherwise does not necessarily constitute or imply its endorsement, recommendation, or favoring by the United States Government or any agency thereof, or Battelle Memorial Institute. The views and opinions of authors expressed herein do not necessarily state or reflect those of the United States Government or any agency thereof.

\author{
PACIFIC NORTHWEST NATIONAL LABORATORY \\ operated by \\ BATTELLE \\ for the \\ UNITED STATES DEPARTMENT OF ENERGY \\ under Contract DE-AC05-76RL01830
}

Printed in the United States of America
Available to DOE and DOE contractors from the Office of Scientific and Technical Information,
P.O. Box 62, Oak Ridge, TN 37831-0062;
ph: (865) 576-8401
fax: $(865) 576-5728$
email: reports@adonis.osti.gov
Available to the public from the National Technical Information Service
5301 Shawnee Rd., Alexandria, VA 22312 ph: (800) 553-NTIS (6847)
email: orders@ntis.gov $<$ http://www.ntis.gov/about/form.aspx $>$
Online ordering: http://www.ntis.gov

This document was printed on recycled paper. 


\section{Restoring Detroit's Street Lighting System}

Bruce Kinzey

September 2015

Prepared for

the U.S. Department of Energy

under Contract DE-AC05-76RL01830

Pacific Northwest National Laboratory

Richland, Washington 99352 



\section{Summary}

The City of Detroit is undertaking a comprehensive restoration of its street lighting system that includes transitioning the existing high-pressure sodium (HPS) sources to light-emitting diode (LED). Detroit's well-publicized financial difficulties over the last several years have added many hurdles and constraints to this process. Strategies to overcome these issues have largely been successful, but have also brought a few mixed results. This document provides an objective review of the circumstances surrounding the system restoration, the processes undertaken and decisions made, and the results so far.

While the lighting transition in Detroit is still ongoing, the new system has already vastly improved on the failed system that preceded it. According to publicized estimates at the time, only about half of the roughly 88,000 total installed units in the old system were in reliable operating condition. Such conditions make it difficult to establish a baseline for comparisons; for example, an overall (but factually inaccurate) assumption that all 88,000 lights were in operating order was necessary to produce postrestoration energy and cost savings estimates in this analysis. Allowing for this and other simplifying assumptions, Table ES.1 summarizes a few of the estimated benefits that can be expected from the street lighting transition once completed in 2016.

Table ES.1. Annual savings ${ }^{a}$ from Detroit street lighting transition

\begin{tabular}{lllccc}
\hline $\begin{array}{l}\text { Annual Energy } \\
\text { Savings (kWh) }\end{array}$ & $\begin{array}{l}\text { Annual } \\
\text { Electric Cost } \\
\text { Savings } \\
(\mathbf{\$})\end{array}$ & $\begin{array}{l}\mathrm{SO}_{2} \\
\text { (tons) }\end{array}$ & $\begin{array}{l}\mathrm{NO}_{\mathrm{x}} \\
\text { (tons) }\end{array}$ & $\begin{array}{l}\mathrm{CO}_{2} \\
\text { (tons) }\end{array}$ & $\begin{array}{l}\mathrm{Hg} \\
\text { (lb) }\end{array}$ \\
\hline $\mathbf{4 5 , 5 9 3 , 1 0 0}$ & $\mathbf{\$ 2 , 9 4 4 , 2 9 6}$ & $\mathbf{1 3 4}$ & $\mathbf{4 1}$ & $\mathbf{4 0 , 4 1 8}$ & $\mathbf{1 . 4 8}$ \\
\hline $\begin{array}{l}{ }^{\mathrm{a}} \text { Based on 88,000 HPS lights in operating condition before restoration and 65,000 LED lights after. } \\
\text { b }\end{array}$ & & & \\
\hline
\end{tabular}

In terms of lighting quality, two of the three application scenarios outlined in the Request for Proposals issued by Detroit in February, 2014 (150 W, $250 \mathrm{~W}$, and $400 \mathrm{~W}$ output equivalents) appear to be producing results that fully meet the terms specified. The $150 \mathrm{~W}$ equivalent application used in residential neighborhoods, however, has intermittent regions within each block of little to no illuminance and fails to meet veiling luminance specifications due to a cost-driven removal of many of the existing street lights, leaving much greater area for each remaining light (on the street corners and mid-block) to cover. Related issues, including removal of lights that were previously among those operating, may underlie some dissatisfaction among city residents.

Ultimately, this transition should offer a much more reliable system, lower operating costs, and fewer problems from copper theft and other issues that plagued the previous system. With this restoration, Detroit is setting a precedent for other municipalities in Southeast Michigan looking to upgrade their aging street lighting infrastructure. 



\section{Contents}

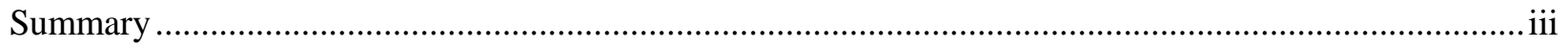

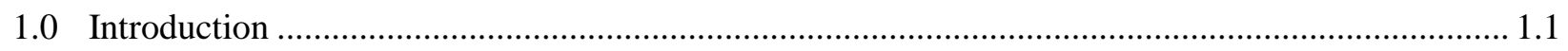

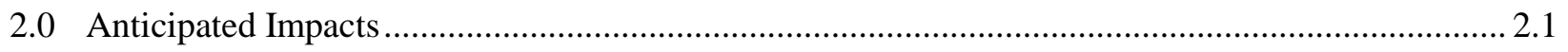

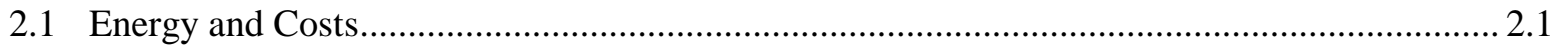

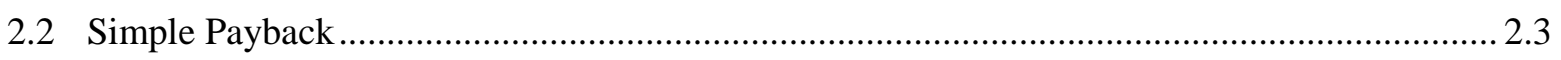

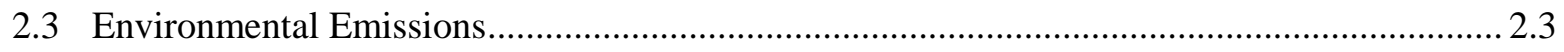

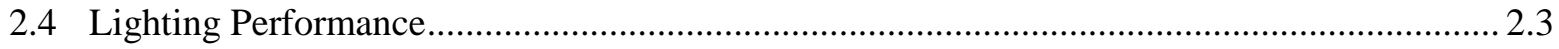

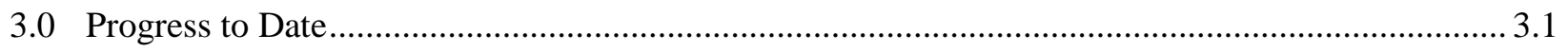

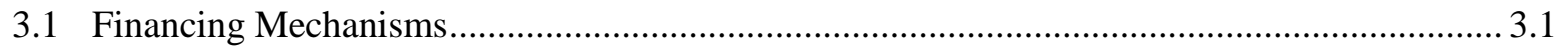

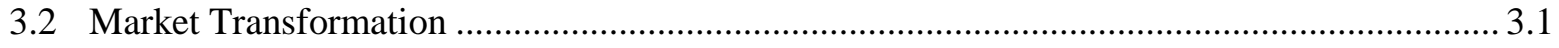

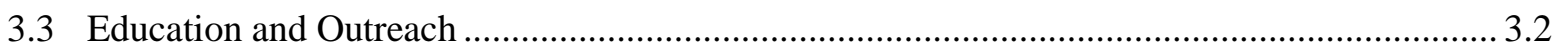

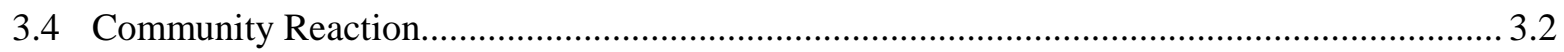

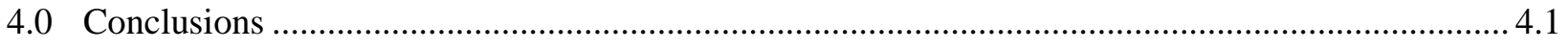

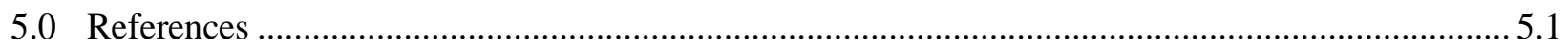

Appendix A Calculation Data Used in Producing Street Lighting Renderings ....................................... A.1

Appendix B Luminance, Glare, and Veiling Luminance Ratio ...............................................................1 


\section{Figures}

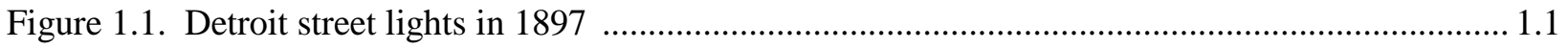

Figure 1.2. Idled Mistersky generators, December 2013 ..................................................................... 1.2

Figure 1.3. Street lighting circuit operating during daytime hours ....................................................... 1.3

Figure 2.1. Illuminance renderings for LED and HPS luminaires in the $150 \mathrm{~W}$ equivalent application.. 2.4

Figure 2.2. Illuminance renderings for LED and HPS luminaires in the $250 \mathrm{~W}$ equivalent application.. 2.5

Figure 2.3. Illuminance renderings for LED and HPS luminaires in the $400 \mathrm{~W}$ equivalent application.. 2.6

\section{Tables}

Table 2.1. Estimated annual energy-only cost for previous 88,000 HPS light system .......................... 2.2

Table 2.2. Estimated annual energy-only cost of replacement LED street lighting system...................... 2.2

Table 2.3. Annual estimated emissions reductions from Detroit's street lighting replacement............... 2.3

Table 2.4. Specified and calculated maintained illuminance values for the $150 \mathrm{~W}$ application............... 2.4

Table 2.5. Specified and calculated illuminance values for the $250 \mathrm{~W}$ application ............................... 2.6

Table 2.6. Specified and calculated illuminance values for the $400 \mathrm{~W}$ application ............................... 2.7

Table 2.7. Maximum veiling luminance ratios for each application scenario ......................................... 2.7 


\subsection{Introduction}

Street lighting in Detroit has a long and storied history. Being one of the earliest U.S. cities to install street and area lighting through a concerted effort of many private sector organizations, Detroit was already considered one of the best-lighted cities in the world by the late 1880s. However, the various organizations installing the lights and wiring were often in competition, creating unnecessary duplication and other inefficiencies throughout the system. To resolve a growing set of problems, in 1893 Mayor Hazen Pingree made a successful case for public ownership of the street lighting system and established the Public Lighting Commission to provide electricity for street lights and the city's buildings. As demand for both electricity and street lighting continued to grow, the city added power plants and expanded generating capacity to keep up. Figure 1.1 shows the significant population of street lights and high-mast carbon-arc "tower lights” that existed in Detroit as early as 1897.

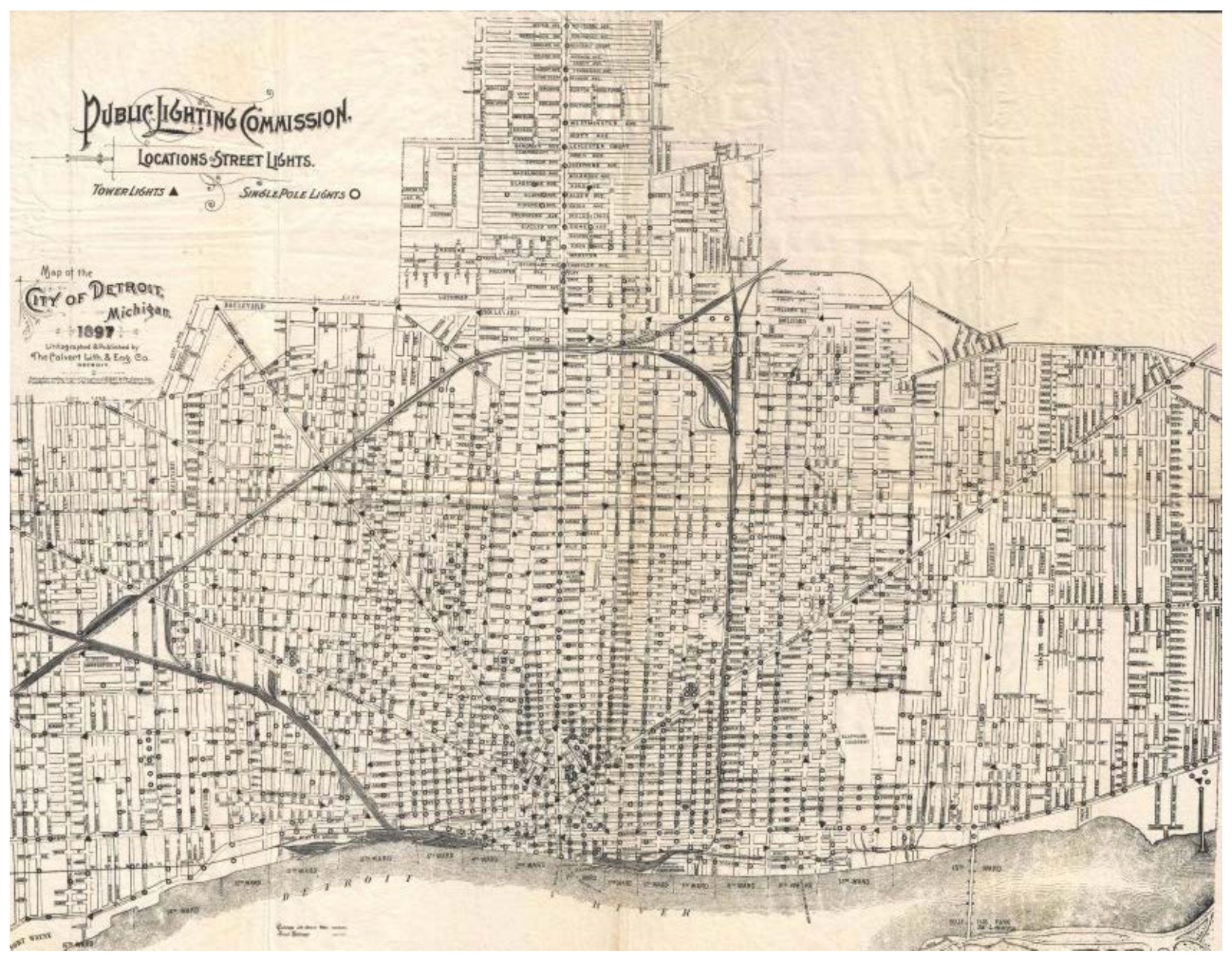

Figure 1.1. Detroit street lights in 1897. Image: Detroit Historical Society

In 1927, the Detroit Public Lighting Commission brought the Mistersky Power Plant online as the system's main source of power, replacing earlier generating capacity owned by the city. Over the ensuing decades, ongoing expansion added new street lights and many other energy customers, including city departments, public schools, police and fire stations, libraries, and Wayne State University. 
By the end of the $20^{\text {th }}$ century, financial woes accompanying a slump in the automotive industry left the city's electrical and street lighting system in a state of visible decay. The Public Lighting Department (successor to the Public Lighting Commission) had reduced its number of employees from more than 800 in the 1970s to less than 100 by 2010. In that year, the aging Mistersky Power Plant was shuttered (Figure 1.2) due to the anticipated cost of bringing it into compliance with modern operating standards, and its generating capacity was supplanted by newer capacity owned by the serving utility, DTE Energy. The utility's capacity was connected to the existing city wiring network via a series of five tie-lines, a move seen as a temporary fix due to the poor condition of the supporting network from those five points inward. Around this same time the City Council made a larger decision to eventually turn over all operation and maintenance of the street lighting and associated electrical infrastructure to DTE Energy.

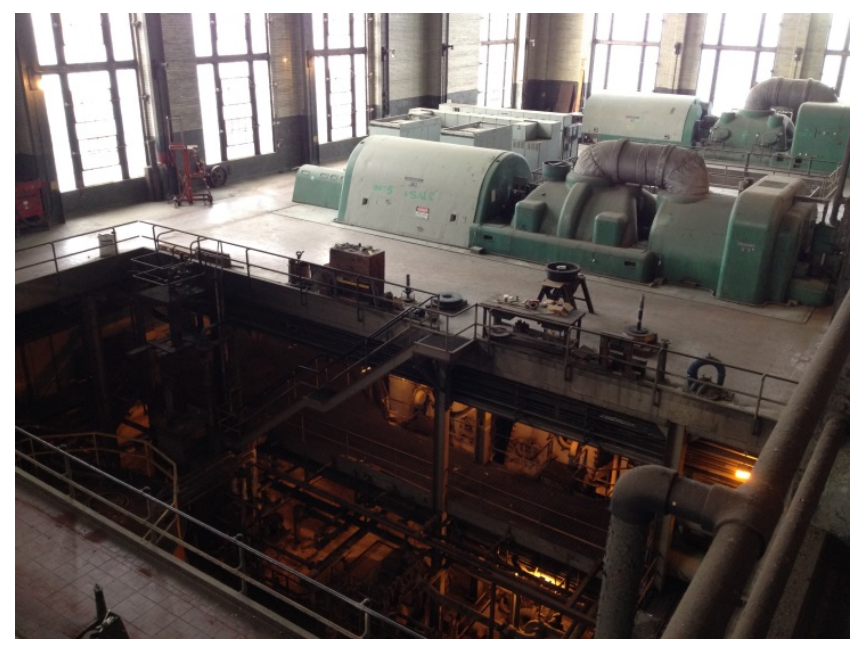

Figure 1.2. Idled Mistersky generators, December 2013. Photo: PNNL

The system continued to suffer from inadequate maintenance, and by mid-2013 it was estimated that more than 50\% of Detroit's 88,000 street lights were no longer functioning. Underlying causes included simple lamp burnouts that the city could not replace in a timely manner due to staff shortages; a growing copper and transformer theft problem; deteriorating wire, pole and substation infrastructure; and an inventory of about 20,000 lights still connected via series-wired circuits, so that one lamp or wire failure would cause all of the luminaires in an entire circuit to go dark.

The system in 2013 also still contained switches on some circuits that had to be manually operated twice per day by city staff. In contrast with the general outage condition of the system, the inability of staff to consistently visit each such location sometimes resulted in entire circuits of "day-burners." See Figure 1.3. 


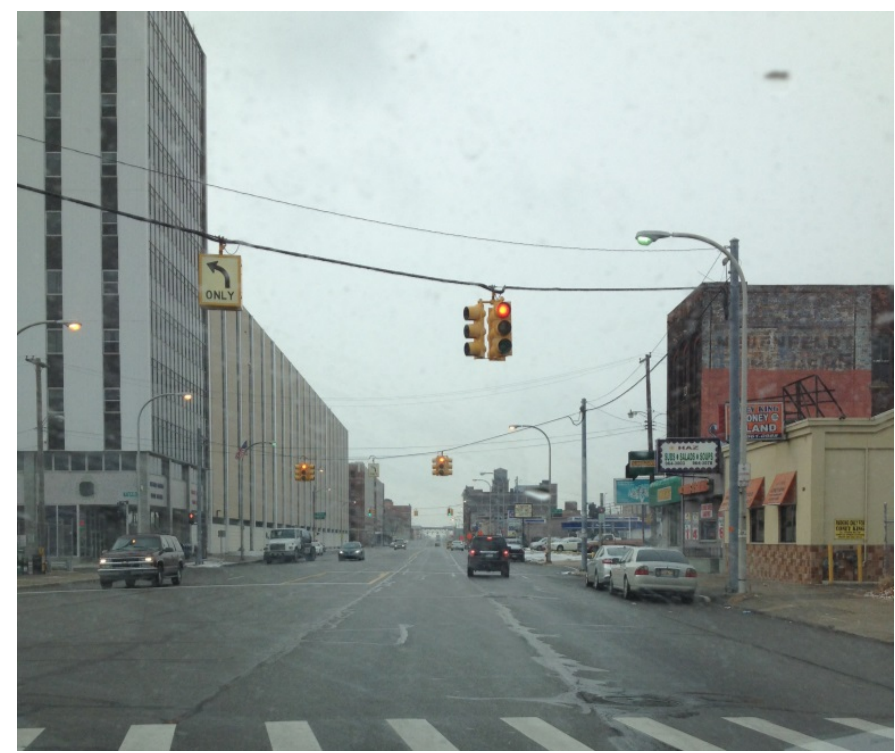

Figure 1.3. Street lighting circuit operating during daytime hours due to an absence of staff to turn it off. Photo: PNNL

By the time Detroit declared bankruptcy in 2013, estimates for returning the overall system to modern standards of operation ranged into the hundreds of millions of dollars. Michigan's governor appointed an Emergency Manager to deal with this and other challenges facing the city, and restoring the street lights was quickly identified as one of the city's top two priorities.

The Emergency Manager promptly established a new agency, the Public Lighting Authority (PLA), to manage restoration of the system. In addition to repair and replacement of most of the street lights, much of the associated wiring and supporting electrical infrastructure also needed replacement due to its deteriorated condition. PLA judged that the previous 88,000 light system was excessive and could not be maintained at the same level following the restoration, particularly in areas of the city where the population had significantly declined. After analyzing the budget, the city set its future design target at approximately 50,000 street lights - a more than $40 \%$ reduction. In working with the Michigan Finance Authority, however, PLA was subsequently able to raise the final number of street lights to 65,000 (see corresponding discussion in Section 3.1 Financing Mechanisms).

Ultimately, LED technology was selected for use throughout the entire system, despite the higher upfront cost compared with a more traditional HPS system. The resulting energy and maintenance savings are expected to more than offset the incremental expenditure for the LEDs. 



\subsection{Anticipated Impacts}

The PLA's highest priority was to get the street lighting system back up and operating as quickly as possible, given that many neighborhoods had lacked reliable street lighting for years. A second priority was to help get the city out of the street lighting business by transferring system operation and maintenance to the serving utility, DTE Energy. The ultimate goal was to provide the most effective street lighting possible given formidable budget and schedule demands.

Like most systems in the U.S., Detroit's street lights are unmetered, meaning that the serving utility calculates a monthly energy charge based on a laboratory-measured power draw of a given luminaire size, including the ballast that powers it. This power level is then multiplied by the average monthly hours of use and then again by the corresponding price the utility charges the city for street light electricity. Finally, the city's monthly power bill is totaled by multiplying the estimated number of luminaires of each size in the system by their corresponding monthly tariffs. One disadvantage to unmetered billing is that the monthly charge for a given light is incurred whether or not that light is operating during the billing cycle. Under typical circumstances for most cities, only a relatively small percentage of street lights are not operating at any given time. However, as noted, by 2013 as much as 50\% or more of Detroit’s lights were dark, yet the city was still responsible for the full energy use of the system.

\subsection{Energy and Costs}

The situation existing at the time PLA was established complicates the process of estimating impacts by confounding the development of an accurate baseline for comparison. In this analysis, given the likelihood that previous billing was based on 88,000 lights whether or not they were entirely operational, comparisons are made against that earlier population of street lights, apportioned among four nominal sizes $(70 \mathrm{~W}, 150 \mathrm{~W}, 250 \mathrm{~W}$, and $400 \mathrm{~W})$. In addition, although it is estimated that as many as 15,000 of these lights were earlier-generation mercury vapor technology, because there are no details on the corresponding wattages and quantities (or how many of each were still working), they are all assumed to be more modern HPS street lights. ${ }^{1}$ Table 2.2 provides an estimate of the monthly energy-only costs (i.e., excluding maintenance) under these assumptions.

\footnotetext{
${ }^{1}$ This assumption tends to make the energy savings estimates conservative, because on a lumens per watt basis the older mercury vapor technology is less efficient than HPS, meaning the resulting savings from substituting LEDs are even greater.
} 
Table 2.1. Estimated annual energy-only cost for previous 88,000 HPS light system

\begin{tabular}{rrrrrr}
\hline $\begin{array}{l}\text { HPS Nominal } \\
\text { Wattage }\end{array}$ & $\begin{array}{l}\text { Charge per } \\
\text { Lamp per } \\
\text { Year }\end{array}$ & $\begin{array}{l}\text { Assumed Number } \\
\text { of Lamps (all } \\
\text { HPS) }\end{array}$ & $\begin{array}{l}\text { Annual Hours } \\
\text { of Operation }\end{array}$ & $\begin{array}{l}\text { Annual kWh } \\
\text { Used }\end{array}$ & $\begin{array}{l}\text { Total Annual } \\
\text { Estimated } \\
\text { Energy Cost }\end{array}$ \\
\hline 70 & $\$ 30.24$ & 15,000 & 4,200 & $5,922,000$ & $\$ 453,600$ \\
\hline 150 & $\$ 64.80$ & 53,000 & 4,200 & $40,068,000$ & $\$ 3,434,400$ \\
250 & $\$ 108.00$ & 13,000 & 4,200 & $16,107,000$ & $\$ 1,404,000$ \\
400 & $\$ 172.80$ & 7000 & 4,200 & $13,671,000$ & $\$ 1,209,600$ \\
& Total: & $\mathbf{8 8 , 0 0 0}$ & & $\mathbf{7 5 , 7 6 8 , 0 0 0}$ & $\mathbf{\$ 6 , 0 4 8 , 0 0 0}$ \\
\hline
\end{tabular}

${ }^{a}$ From DTE Electric Company Rate Book for Electric Service, Sheet No. D-53.00. "Where the municipality owns, operates, cleans and renews the lamps, and the Company's service is confined solely to the supply of electricity from dusk to dawn, the monthly charge of said service shall be $3.60 \$$ per nominal connected watt per month of lamps so served.” DTE also assumes 4200 hours per year operation.

Table 2.2. Estimated annual energy-only cost of replacement LED street lighting system

\begin{tabular}{lllllll}
\hline HPS & Wattage of & Number of & Calculated & Annual & Annual kWh & Annual \\
Nominal & LED & Units To & Cost of & Hours of & Used & Estimated \\
Wattage & Replacement & Be & Electricity & Operation & & Energy Cost \\
To Be & Product & Replaced & $(\$ / k W h)^{\mathbf{a}}$ & & & \\
Replaced & & & & & &
\end{tabular}

\begin{tabular}{rrrrrrr|}
\hline 150 & 88.2 & 45,000 & $\$ 0.103$ & 4200 & $16,669,800$ & $\$ 1,714,608$ \\
250 & 106.0 & 13,000 & $\$ 0.103$ & 4200 & $5,787,600$ & $\$ 595,296$ \\
400 & 262.5 & 7,000 & $\$ 0.103$ & 4200 & $7,717,500$ & $\$ 793,800$ \\
& Total: & $\mathbf{6 5 , 0 0 0}$ & & & $\mathbf{3 0 , 1 7 4 , 9 0 0}$ & $\mathbf{\$ 3 , 1 0 3 , 7 0 4}$ \\
\hline
\end{tabular}

${ }^{a}$ Calculated from the existing DTE standard rate of 3.60® per nominal connected watt per month and 4200 hours per year operation.

The anticipated savings from the new 65,000 unit LED system compared to the previous 88,000 unit HPS system therefore amounts to about $\mathbf{4 6}$ million $\mathbf{~ W W h}$ in electricity and $\mathbf{\$ 2 . 9}$ million per year in energy costs. If instead the LED system is compared to a restored HPS system of 65,000 lights at the same wattages and quantities displayed in Table 2.2, the LED system annually saves about 34 million $\mathrm{kWh}$ in electricity, valued at $\$ 2.4$ million. ${ }^{2,3}$

Maintenance savings are more difficult to quantify than energy savings given the extraordinary circumstances surrounding the failed condition of the previous system. Certainly the conventional need for relamping fixtures every 4-5 years will be eliminated following the substitution of LED luminaires, although they eventually need replacement as well (perhaps on a 15-20 year cycle). In addition, the lower power demands of the LEDs has allowed the city to install replacement distribution wire made from aluminum instead of copper; aluminum has a much lower inherent value and thereby presents not only a

\footnotetext{
${ }^{2}$ The calculated savings rate $(\$ / \mathrm{kWh})$ differs among these comparisons because they are based on nominal wattage of the luminaire, and thus ignore ballast wattage in the HPS (effectively lowering its corresponding rate).

${ }^{3}$ A post-restoration system of 65,000 HPS lights might provide a better baseline comparison because of the nonworking condition of much of the previous system and the transition's elimination of 23,000 lights.
} 
cheaper first cost but also a much less desirable target for thieves. Combined with a ten-year luminaire warranty, future maintenance costs of the updated street lighting system are expected to be quite low.

\subsection{Simple Payback}

Preliminary price quotes for the three LED units from a product vendor ${ }^{4}$ yield a total estimated cost of $\$ 12$ million for the 65,000 replacement units. Because the previous lighting system required repair and replacement regardless of the source technology, the cost relevant to this calculation is the incremental cost of the LEDs compared to a possible HPS alternative. Costs of installation and any infrastructure modifications are assumed to be identical, although in fact the lower-cost aluminum wiring being installed with the LED products saves additional capital costs relative to the copper needed for a conventional system. Assuming a very low average cost of $\$ 100$ for a conventional cobrahead luminaire (including ballast), simple payback on the additional investment to purchase LEDs is thus achieved in about 2.3 years from the energy savings alone. Maintenance savings will further shorten this period.

\subsection{Environmental Emissions}

The precision of environmental emissions estimates depends on the particular mix of generating capacity used by a utility and how that evolves over a 24-hour period (i.e., capacity used at night is likely only a select subset of that used during peak daytime periods). The mix is furthermore likely to change yearly as older capacity is retired or upgraded and new capacity is added. Table 2.3 provides estimates of the annual reduction in environmental emissions based on rates reported for 2010, and thus does not take such variances into account. These reductions again correspond to the conversion of an original system of 88,000 operating HPS lights to 65,000 LED lights.

Table 2.3. Annual estimated emissions reductions from Detroit’s street lighting replacement

\begin{tabular}{lc}
\hline & Annual Reduction \\
\hline Annual kWh Savings from Pre- to Post-LED: & $45,593 \mathrm{MWh}$ \\
$\mathrm{SO}_{2}$ & 134 tons \\
$\mathrm{NO}_{\mathbf{x}}$ & 41 tons \\
$\mathrm{CO}_{2}$ & 40,418 tons \\
$\mathbf{H g}$ & $1.48 \mathrm{lb}$ \\
\hline
\end{tabular}

${ }^{\mathrm{a}}$ Based on 2010 emission rates of DTE Energy. Data source: Bradley \& Associates, 2012.

\subsection{Lighting Performance}

Detroit's original lighting system included alleyways and multiple lights on every residential block. Historically however, the specific location of individual lights in Detroit's neighborhoods sometimes appear to have been chosen almost ad hoc rather than based on a uniform and coordinated plan. Combined with anticipated budget limitations going forward, PLA concluded that the best action was to reduce the number of luminaires installed on a typical neighborhood street, thus reducing both present capital and future operating costs. For a typical 600-foot block, for example, the new design might include a light pole on each corner and one in the center (yielding a 300-foot pole spacing), and removing all other street lights.

\footnotetext{
${ }^{4}$ As reported by PLA via email April 16, 2014.
} 
In fact, the luminaire specification issued by PLA to solicit vendor proposals went a step further, extending the design pole spacing in the neighborhoods (i.e., the $150 \mathrm{~W}$ application scenario) to 350 feet while retaining the original mounting height of 25 feet. ${ }^{5}$ Figure 2.1 provides a calculated rendering of how the resulting illumination appears on such a street, based on the specified maintained values ${ }^{6}$ and the manufacturers' photometric files for the respective LED product being installed (as listed in Table 2.4). For comparison, a corresponding rendering of a modern, widely-used $150 \mathrm{~W}$ HPS product is also provided. All lumen outputs listed in the following figures refer to luminaire rather than source output.

Pole

\section{W LED - 8066 lumens (initial), 6170 lumens (maintained):}

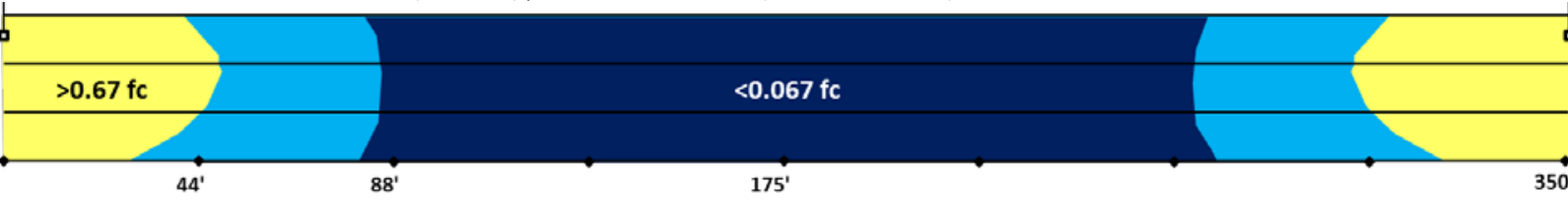

150 W HPS cobrahead (183 W incl. ballast)- 10,645 lumens (initial), 8,622 lumens (maintained):

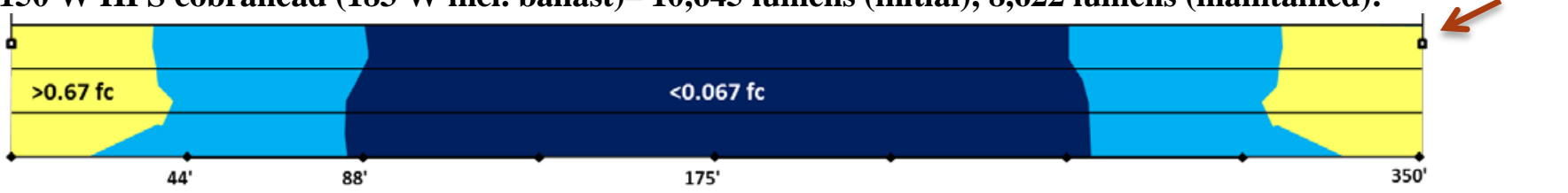

Figure 2.1. Illuminance renderings for LED and HPS luminaires in the specified $150 \mathrm{~W}$ equivalent application (350 foot pole spacing, 25 foot mounting height)

Table 2.4. Specified and calculated maintained illuminance values (average value and uniformity ratio) for the $150 \mathrm{~W}$ application

\begin{tabular}{|c|c|c|c|c|}
\hline \multicolumn{5}{|c|}{ Roadway Illuminance Metric } \\
\hline & PLA Spec & $\begin{array}{c}\text { Recommended } \\
\text { Practice }^{\mathrm{a}}\end{array}$ & $\begin{array}{c}\text { Calculated HPS } \\
\text { Performance }\end{array}$ & $\begin{array}{c}\text { Calculated LED } \\
\text { Performance }\end{array}$ \\
\hline $\operatorname{avg}(f c)$ & 0.4 & -- & 0.5 & 0.4 \\
\hline avg:min & -- & $6: 1$ & $>100: 1$ & $>100: 1$ \\
\hline $\max : \min$ & -- & $10: 1$ & $>100: 1$ & $>100: 1$ \\
\hline
\end{tabular}

At this scale the two source technologies appear quite similar in terms of illuminance levels and distribution, both supplying high levels of lighting at the intersections while leaving areas of darkness between street lights. The different colors in the graphics correspond to a combination of the illuminance requirements in the Detroit specification and related uniformity ranges that follow the recommended guidelines in IES/ANSI RP-8-00 (IES, 2005 reaffirmed). ${ }^{7,8}$ The darkest blue areas are calculated using the

\footnotetext{
${ }^{5}$ The lighting quality measures contained in Detroit's February 2014 luminaire specification and the criteria used to produce the corresponding graphics in this document are summarized in Appendix A.

${ }^{6}$ The following light loss factors are used in this analysis: HPS fixtures: LLF $=0.81$ (LLD of 0.90 and LDD of 0.90); LED fixtures: $L L F=0.765$ (LLD of 0.85 and LDD of 0.90). For LED, the PLA spec states an LDD of 0.90 as per DG-4 (IES, 2014c) but for LLD, the value used is a percentage of initial output calculated in accordance with LED Lighting Facts ${ }^{\circledR}$ program requirements. A value of 0.85 was thus assumed to represent average performance.

${ }^{7}$ The Detroit luminaire specification did not expressly require that luminaires proposed by bidders meet RP-8. IES Recommended Practices are widely used across North America and provide guidelines for different lighting applications under different conditions, but are voluntarily adopted by individual agencies as desired and applicable.
} 
specified maintained average illuminance of 0.4 footcandles (fc) and a corresponding IES avg:min recommended uniformity ratio of 6:1. All points within the darkest areas thus fall below an illuminance that would yield that recommended uniformity, given a $0.4 \mathrm{fc}$ average (i.e., $1 / 6$ of 0.4 or $0.067 \mathrm{fc}$ ). In contrast, the lightest areas (yellow) near the poles are derived from the corresponding IES recommended max:min luminance uniformity ratio of 10:1 (i.e., 10 times 0.067 or $0.67 \mathrm{fc}$ ). All points in the yellow areas thus exceed a uniformity recommended by IES, based on the specified 0.4 fc maintained average. The intermediate-shaded areas (light blue) correspond to the areas on this theoretical street where the illumination is meeting both the specified maintained average and the IES-recommended uniformities. ${ }^{9}$

Figure 2.2 and Figure 2.3 were generated similarly to those of the $150 \mathrm{~W}$ equivalent scenario for neighborhoods and use the same shading schemes. However, they pertain to larger physical scenarios (i.e., higher-speed roadways) with higher equivalent wattages (250 W and $400 \mathrm{~W}$, respectively) and the original pole configurations are the same as before the restoration. The LED and HPS sources in both applications essentially meet the recommended minimum illumination levels throughout the target space, although maximum levels that would remain within the recommended uniformity limits are exceeded in areas using the HPS product.

\section{W LED: 9,680 lumens (initial), 7,405 lumens (maintained):}

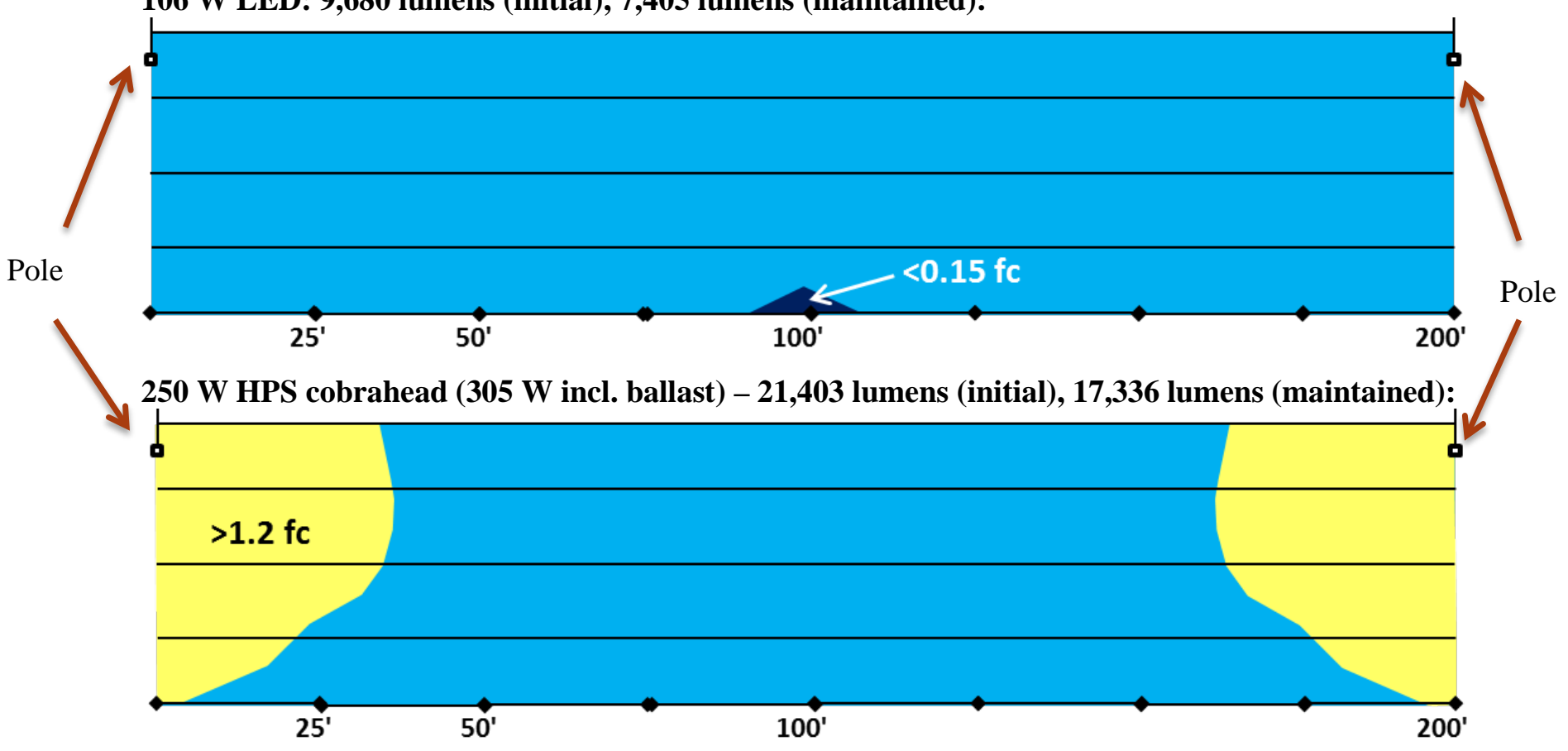

Figure 2.2. Illuminance renderings for LED and HPS luminaires in the specified $250 \mathrm{~W}$ equivalent application (200 foot pole spacing, 35 foot mounting height)

In this case, for example, it would be futile to require luminaires to meet RP-8 because no commercially available street lighting product mounted at 25 feet could achieve the illuminance, uniformity and glare stipulations across such an extensive pole spacing. Much of the region at the center of Figure 2.1 receives negligible illumination ( 0.0 fc) from the lights at either end.

${ }^{8}$ A 2014 update is now also available, but was not yet published (or a basis of design) when Detroit issued the RFP.

${ }^{9}$ It should be noted that in practice, satisfying the recommended set of ranges everywhere on any given street is frequently unachievable due to variations in pole spacing, ground contours, vegetation, conflicts between competing criteria and other factors, and hence these values’ official status as "recommended guidelines." 
Table 2.5. Specified and calculated illuminance values (average value and uniformity ratio) for the 250 W application

\begin{tabular}{lcccc}
\hline \multicolumn{5}{c}{ Roadway Illuminance Metrics } \\
\hline PLA Spec & $\begin{array}{c}\text { Recommended } \\
\text { Practice }^{\mathbf{a}}\end{array}$ & $\begin{array}{c}\text { Calculated HPS } \\
\text { Performance }\end{array}$ & $\begin{array}{c}\text { Calculated LED } \\
\text { Performance }\end{array}$ \\
\hline avg (fc) & 0.6 & -- & 1.1 & 0.6 \\
avg:min & $4: 1$ & -- & $3.2: 1$ & $3.9: 1$ \\
\hline max:min & -- & $8: 1$ & $14.6: 1$ & $7.6: 1$ \\
${ }^{\text {a }}$ Based on corresponding luminance ratios recommended in RP-8. \\
\hline
\end{tabular}

Note that the application scenario shown in Figure 2.3 includes seven lanes of traffic, and in contrast with Figure 2.1 and Figure 2.2, a sidewalk on each side of the roadway. In this case the HPS comparison product, in particular, provides a significant amount of overlighting, as indicated by the yellow region exceeding the recommended max:min level of illumination. ${ }^{10}$

\section{W LED - 24,112 lumens (initial), 18,446 lumens (maintained): \\ $400 \mathrm{~W}$ HPS cobrahead (468 W w/ballast) - 37,001 lumens (initial), 29,971 lumens}

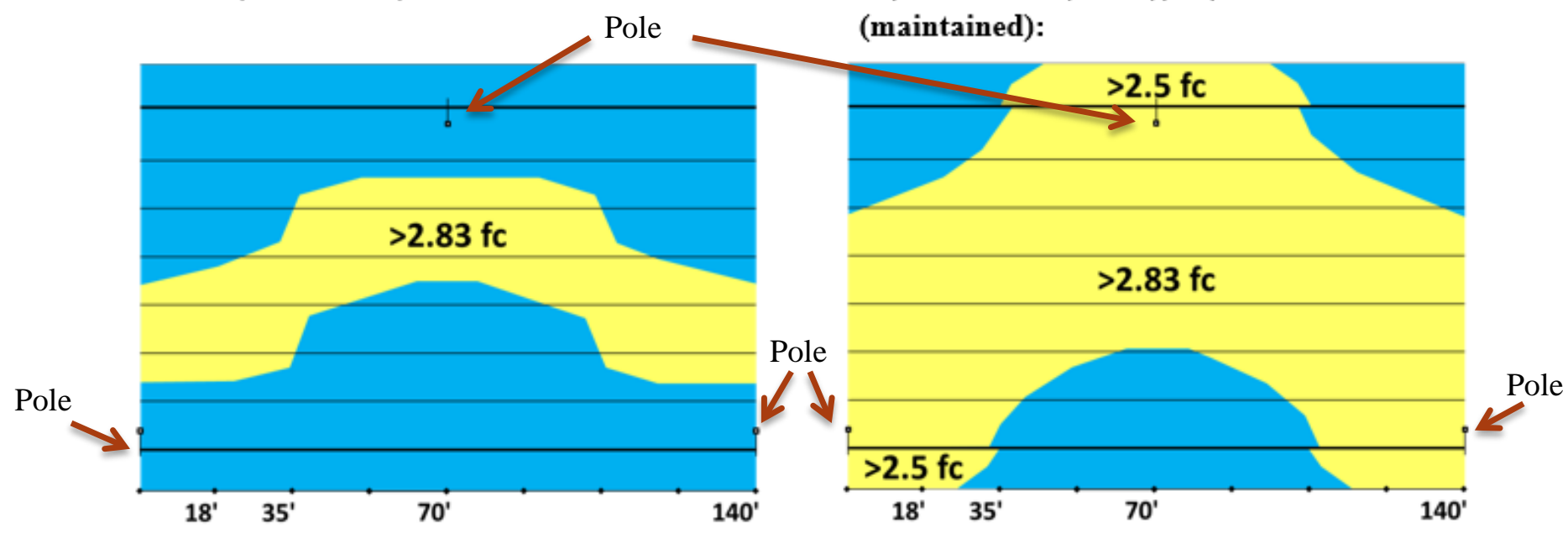

Figure 2.3. Illuminance renderings for LED and HPS luminaires in the specified $400 \mathrm{~W}$ equivalent application (140 foot staggered spacing, 35 foot mounting height)

\footnotetext{
${ }^{10}$ The yellow regions in Figure 2.3 indicate that there is more light being provided to these corresponding areas than needed to meet the specified average illuminance. The Detroit spec, however, did not include a requirement for either maximum or minimum illuminance, in favor of only the average. For this reason both the LED and HPS luminaires are technically meeting the terms of the $400 \mathrm{~W}$ specification on the roadway surface.
} 
Table 2.6. Specified and calculated illuminance values (average value and uniformity ratio) for the 400 W application

\begin{tabular}{|c|c|c|c|c|}
\hline & \multicolumn{4}{|c|}{ Roadway Illuminance Metrics } \\
\hline & PLA Spec & $\begin{array}{l}\text { Recommended } \\
\text { Practice }^{\mathrm{a}}\end{array}$ & $\begin{array}{l}\text { Calculated HPS } \\
\text { Performance }\end{array}$ & $\begin{array}{c}\text { Calculated LED } \\
\text { Performance }\end{array}$ \\
\hline $\operatorname{avg}(\mathrm{fc})$ & 1.7 & -- & 3.5 & 2.6 \\
\hline avg:min & $3: 1$ & -- & $2.2: 1$ & $1.7: 1$ \\
\hline \multirow[t]{3}{*}{ max:min } & -- & $5: 1$ & 3.6:1 & $2.2: 1$ \\
\hline & \multicolumn{4}{|c|}{ Sidewalk Illuminance Metrics } \\
\hline & PLA Spec & $\begin{array}{l}\text { Recommended } \\
\text { Practice }^{\mathrm{a}}\end{array}$ & $\begin{array}{l}\text { Calculated HPS } \\
\text { Performance }\end{array}$ & $\begin{array}{l}\text { Calculated LED } \\
\text { Performance }\end{array}$ \\
\hline $\operatorname{avg}(\mathbf{f c})$ & 2 & -- & 2.3 & 1.5 \\
\hline avg:min & $4: 1$ & -- & 1.9:1 & 1.4:1 \\
\hline $\max : \min$ & -- & $5: 1$ & $3.5: 1$ & $1.9: 1$ \\
\hline
\end{tabular}

Table 2.6 indicates that both LED and HPS products meet the terms of the specification, except on the sidewalk where the LED average illuminance falls slightly below the specified value (shown in red).

The Detroit specification also contained requirements for maximum veiling luminance ratio, requesting a value for all three applications of $\leq 0.4$. Veiling luminance refers to the effect of bright objects in the visual field causing visibility and visual performance to decrease (see Appendix B for a more detailed discussion). The specific ratio results from a complex calculation that essentially compares the brightness of the luminaires to the corresponding average pavement luminance; lower values generally indicate a lower incidence of disabling glare and vice-versa.

Table 2.7 provides the calculated veiling luminance ratios for each application, again based on the photometric files from a widely used HPS manufacturer and the LED products being installed.

Table 2.7. Maximum veiling luminance ratios for each application scenario

\begin{tabular}{cccc}
\hline & \multicolumn{3}{c}{ Maximum veiling luminance ratio } \\
\hline HPS equivalent & PLA spec & HPS performance & LED performance \\
150 W & 0.4 & 0.87 & 1.00 \\
$\mathbf{2 5 0}$ W & 0.4 & 0.40 & 0.40 \\
$\mathbf{4 0 0}$ W & 0.4 & 0.19 & 0.22 \\
\hline
\end{tabular}

Both the LED and HPS products again satisfy the terms of the Detroit specification in the $250 \mathrm{~W}$ and $400 \mathrm{~W}$ scenarios, but fall significantly short in the $150 \mathrm{~W}$ scenario. The values in red suggest that contrasts between light and dark areas on such a street are excessive and may prevent an acceptable level of visibility between regions. 



\subsection{Progress to Date}

Installation of the luminaires began in earnest in April 2014, and the PLA website reports more than 48,000 street lights replaced by August 2015. PLA expects to complete all neighborhood replacements by December 2015 and all thoroughfare replacements in 2016.

In parallel with the lighting transition, the remaining infrastructure continues to be either repaired and replaced, or supplanted by new DTE equipment and decommissioned. Much of the older equipment and substation property requires environmental remediation before the sites can be returned to the city for redevelopment or other use; for now the decommissioned sites are being secured after any dangerous material is removed.

In addition to residential street lights, PLA also plans to remove alleyway lighting, although residents will have the option to keep them if willing to pay for them separately. Also, in cases where individual neighborhoods want to upgrade from standard to decorative-style LED luminaires, PLA contributes the allocated funds to the residents to purchase the style they want and installs the luminaires at no additional cost as long as the residents fund any incremental first cost themselves.

\subsection{Financing Mechanisms}

Around the time the RFP was issued, the planned budget for the system replacement (including extensive repairs to the supporting electrical infrastructure) was $\$ 160$ million and would have resulted in a system of roughly 50,000 street lights. Detroit acquired a short-term loan for $\$ 60$ million to initiate the process while a longer-term bond issue was put together and passed. Because PLA, working with the Michigan Finance Authority, was able to sell the bonds at a better interest rate than planned, their total sale increased to $\$ 185$ million and the final number of street lights was raised to 65,000 . The city is repaying the bond in part with $\$ 12$ million per year in allocations from a utility user tax that generates approximately $\$ 42$ million per year in total revenue.

\subsection{Market Transformation}

Detroit's successful street lighting restoration is setting a precedent for communities throughout Southeast Michigan. Aging infrastructure and a need to reduce municipal costs are attracting much attention to Detroit's program and its reception by the community and the serving utility, DTE Energy.

Unlike Detroit, most other municipalities in Southeast Michigan do not own their street lights aside from older inventory in the downtown sections, often comprised of decorative-style post top luminaires. DTE Energy owns an estimated $90 \%$ or more of the street lighting infrastructure in its service territory outside of Detroit. The utility currently offers a limited LED option to these customers with a restricted number of annual upgrades using products from a single manufacturer, primarily targeted toward replacement of older mercury vapor luminaires. Replacement of newer HPS luminaires, in contrast, entails additional stranded asset charges to the municipality and is therefore less cost-effective from their perspective.

Detroit's program is raising awareness of the potential savings and other benefits from a street lighting upgrade, however, and many surrounding cities have intensified their efforts to follow suit. A recent utility filing with the Michigan Public Service Commission, for example, proposing to increase LED tariff rates while simultaneously reducing the corresponding HPS rates, has met with much resistance 
from other municipalities in DTE Energy's service territory. ${ }^{1}$ Approximately 20 cities and associated representatives had joined to intervene in the rate case hearing as of March $2015 .^{2}$

\subsection{Education and Outreach}

Detroit has made extensive efforts to communicate with its citizens about the street lighting upgrade, owing to its high priority in the city's recovery plan. Both the Mayor's Office and PLA have held public meetings and media appearances and have added information about the upgrade on their websites. The PLA website provides a schedule of upcoming meetings that are open to the public and in some cases provide a forum to ask questions and give feedback directly to the principals involved. The PLA website also provides the overall plan and status of the installation schedule, an opportunity to report outages, and updates on outages previously reported. The website effectively presents a friendly public face of the PLA.

\subsection{Community Reaction}

According to most media reports, the local reception to Detroit's updated lighting system is generally positive, no doubt enhanced by the years of non-operating street lights. In a few cases, however, residents have been predictably disappointed to find that a previously-operating light in front of their house was removed in the process. The 300+ foot residential pole spacing is a very long throw for any type of shielded luminaire, and consequently there are significant areas of darkness and related glare issues in the spaces between poles, sometimes also yielding a negative response.

\footnotetext{
${ }^{1}$ Detroit has a separately negotiated contract so is not immediately subject to the same rates.

${ }^{2}$ MPSC Rate Case No. U-17767.
} 


\subsection{Conclusions}

Detroit has overcome a significant challenge in returning its street lighting system to reliable operation in a very short time and with sharply limited resources. Given the circumstances present at the time the project was planned and executed, however, whether the specific approaches taken are appropriate for other municipalities must be evaluated case-by-case.

Highlights of Detroit's street lighting upgrade include the following:

- The new LED system will save about 46 million $\mathrm{kWh}$ (60\%), worth about $\$ 2.9$ million, every year compared to the old HPS system (allowing the assumption that all previous 88,000 lights were in working order).

- Compared to an alternative but comparable replacement system of 65,000 HPS street lights, the LED system saves about 34 million kWh (53\%) per year, worth about $\$ 2.4$ million. ${ }^{1}$

- The incremental investment in LED products was easily justified, offering a simple payback of less than 2.5 years from energy savings alone (i.e., ignoring additional maintenance savings).

- Compared with the old lighting system, the new one is expected to improve reliability and safety, improve resistance to vandalism, and decrease opportunities for theft.

- The new system generally delivers higher quality illumination compared with the previous system, where at least half of the street lights were not operating regularly; however, the quality of illumination in the residential neighborhoods has been slightly compromised compared to what it might have been because of the removal of poles and luminaires. The distance between the remaining poles is too great for any traditional luminaire to overcome, regardless of the lighting technology used. Areas of darkness and associated glare from nearby street lights are likely issues for some residents.

- As in many other locations around the country, the system was already (at least theoretically) operating with sufficient cash flow to finance a lighting transition, as long as energy and maintenance cost savings could be retained to repay the cost of borrowed capital. Given the bankruptcy proceedings surrounding this case, a different source of funds was required, namely, a portion of the proceeds from a utility user's tax.

- Detroit's decision to establish an independent agency, the PLA, to deal with funding and manage the transition was necessary to address the multiple challenges the city faced regarding its bankruptcy filing.

- Going forward, the city should closely document its actual costs of street light operation, including energy, maintenance and repayment of the capital costs, as the current contract between PLA and DTE Energy has only a three-year lifespan; at that point the city and PLA will be renegotiating the costs of their continuing utility service and the city will want to be able to accurately compare the historical data with the expenditures proposed in the new contract.

\footnotetext{
${ }^{1}$ As previously noted, the calculated savings rate $(\$ / \mathrm{kWh})$ differs among these comparisons because they are based on nominal wattage of the luminaire, and thus ignore ballast wattage in the HPS (effectively lowering its corresponding rate).
} 



\subsection{References}

DTE Electric Company, 2014. Rate Book for Electric Service, issued May 20, 2014. Accessed March 18, 2015 at https://www2.dteenergy.com/wps/wcm/connect/2ab3cd68-cf7b-4946-9a14f9a8d62a20de/detroitEdisonTariff.pdf?MOD=AJPERES.

Illuminating Engineering Society of North America (IES), 2005. Roadway Lighting, ANSI/IES RP-8-00. Reaffirmed 2005. New York, New York.

Illuminating Engineering Society of North America (IES), 2014a. Roadway Lighting, ANSI/IES RP-814. July 2014. New York, New York.

Illuminating Engineering Society of North America (IES), 2014b. The Lighting Handbook, $10^{\text {th }}$ Edition. New York, New York.

Illuminating Engineering Society of North America (IES), 2014c. Design Guide for Roadway Lighting Maintenance. ANSI/IES DG-4-14. New York, New York.

MJ Bradley \& Associates, 2012. Benchmarking Air Emissions of the 100 Largest Electric Power Producers in the United States. July 2012. Accessed at http://www.nrdc.org/air/pollution/benchmarking/files/benchmarking-2012.pdf. 

Appendix A

Calculation Data Used in Producing Street Lighting Renderings 



\section{Appendix A}

\section{Calculation data ${ }^{1}$ used in producing street lighting renderings}

150 W equivalent application:

a. Values in Specification: 33' roadway width, 3 lanes, 350' one-sided spacing, 2' setback for luminaires, 25' mounting height, 6' arm length, minimum 0.4 fc average maintained horizontal illuminance at pavement, $125 \mathrm{~W}$ max LED input power, R3 pavement, 0.4 maximum veiling luminance ratio

b. Isoilluminance lines calculation factors used in Figure 4:

$\circ \quad 0.40 \mathrm{fc}$ (PLA required average maintained horizontal illuminance) divided by 6 (standard avg:min ratio, not specified in spec) $=0.067 \mathrm{fc}$ (minimum value that complies with average requirements)

$\circ \quad 0.067$ times 10 (standard max:min ratio for $150 \mathrm{~W}$ luminaire, not specified in spec) $=0.67 \mathrm{fc}$ (maximum value that complies with uniformity requirements)

250 W equivalent application:

a. Values in Specification: 44' roadway width, 4 lanes, 200' one-sided spacing, 2' setback for luminaires, 35' mounting height, 6' arm length, minimum 0.6 fc average maintained horizontal illuminance at pavement, 4:1 illuminance uniformity ratio (avg:min), $200 \mathrm{~W}$ max LED input power, R3 pavement, 0.4 maximum veiling luminance ratio

b. Isoilluminance lines calculation factors used in Figure 5:

$\circ \quad 0.6 \mathrm{fc}$ (PLA required average maintained horizontal illuminance) divided by 4 (avg:min ratio, specified in PLA spec) $=0.15 \mathrm{fc}$ (minimum value that complies with average requirements)

○ 0.15 times 8 (standard max:min ratio for $250 \mathrm{~W}$ luminaire, not specified in spec) $=1.2 \mathrm{fc}$ (maximum value that complies with uniformity requirements)

400 W equivalent application:

a. Values in Specification: 77' roadway width, 7 lanes, 140' staggered spacing, 2' setback for luminaires, 35' mounting height, 6' arm length, minimum 1.7 fc (roadway) and 2 fc (sidewalk) average maintained horizontal illuminance at pavement, 3:1 (roadway) and 4:1 (sidewalk) illuminance uniformity ratio (avg:min), $1 \mathrm{fc}$ maintained minimum vertical illuminance at 4.9' (sidewalk), $325 \mathrm{~W}$ max LED input power, R3 pavement, 10' sidewalk (both directions), 0.4 maximum veiling luminance ratio

b. Isoilluminance lines calculation factors used in Figure 6 (pertaining to road surface):

$\circ 1.7 \mathrm{fc}$ (PLA required average maintained horizontal illuminance) divided by 3 (avg:min ratio, specified in PLA spec) $=0.567 \mathrm{fc}$ (minimum value that complies with average requirements)

$\circ \quad 0.567 \mathrm{fc}$ times 5 (standard max:min ratio, not specified in spec) $=2.83 \mathrm{fc}$ (maximum value that complies with uniformity requirements)

\footnotetext{
${ }^{1}$ Data derived from a combination of: a) lighting scenario specifications contained in the Detroit Request for Proposals (issued February 2014), and b) uniformity factors derived from other IES RP-8 recommendations.
} 
c. Isoilluminance lines calculation factors used in Figure 6 (pertaining to sidewalk):

- 2 fc (PLA required average maintained horizontal illuminance) divided by 4 (avg:min ratio, specified in PLA spec) $=0.5 \mathrm{fc}$ (minimum value that complies with average requirements)

$\circ \quad 0.5 \mathrm{fc}$ times 5 (standard max:min ratio, not specified in spec) $=2.5 \mathrm{fc}$ (maximum value that complies with uniformity requirements) 


\section{Appendix B}

\section{Luminance, Glare, and Veiling Luminance Ratio}





\section{Appendix B}

\section{Luminance, Glare and Veiling Luminance Ratio}

Definitions derived from IES/ANSI RP-8-14 (IES, 2014a) and The Lighting Handbook $10^{\text {th }}$ Edition (IES, 2014b):

Illumination describes the general circumstance of light incident on a surface or body.

Illuminance refers to the quantity of incident light on a surface.

Luminance is the light-emitting power of a surface in a particular direction, per unit area. The light can be either emitted from that surface, as from a lamp, or reflected from that surface, as from a roadway.

Glare is the sensation produced by luminance within the visual field that is significantly greater than the luminance to which the eyes are adapted, which results in discomfort or loss in visibility.

Disability glare is glare that results in reduced visual performance and visibility. It is caused by intraocular scattering of light which creates a veil of luminance over the target image and results in reduced contrast.

Veiling luminance is a luminance superimposed on the retinal image which reduces its contrast. It is this veiling effect produced by bright sources or areas in the visual field that results in decreased visual performance and visibility.

\section{Discussion:}

The criterion used for roadway lighting to address disability glare is limiting the veiling luminance ratio of a lighting system. RP-8 addresses disability glare by recommending a limit for the ratio of the maximum veiling luminance to the average pavement luminance (i.e., some glare is acceptable if the corresponding pavement illumination is commensurate).

In the $150 \mathrm{~W}$ scenario described in this document, the intermittent removal of street lights in the midblock regions results in significant areas receiving no appreciable light contribution from street lights that are as much as 175 feet away in either direction. The adaptation of an observer's eye to the corresponding levels of illumination will be unsuited to the comparatively bright luminance emanating from the nearest street light, as indicated by the values reported in Table 4, reproduced below.

Table 4 (reproduced). Maximum veiling luminance ratios for each application scenario

\begin{tabular}{cccc}
\hline & \multicolumn{3}{c}{ Maximum veiling luminance ratio } \\
\hline HPS equivalent & PLA spec & HPS performance & LED performance \\
\hline $\mathbf{1 5 0} \mathbf{~ W}$ & 0.4 & 0.87 & 1.00 \\
$\mathbf{2 5 0} \mathbf{~ W}$ & 0.4 & 0.34 & 0.40 \\
$\mathbf{4 0 0} \mathbf{~ W}$ & 0.4 & 0.19 & 0.22 \\
\hline
\end{tabular}






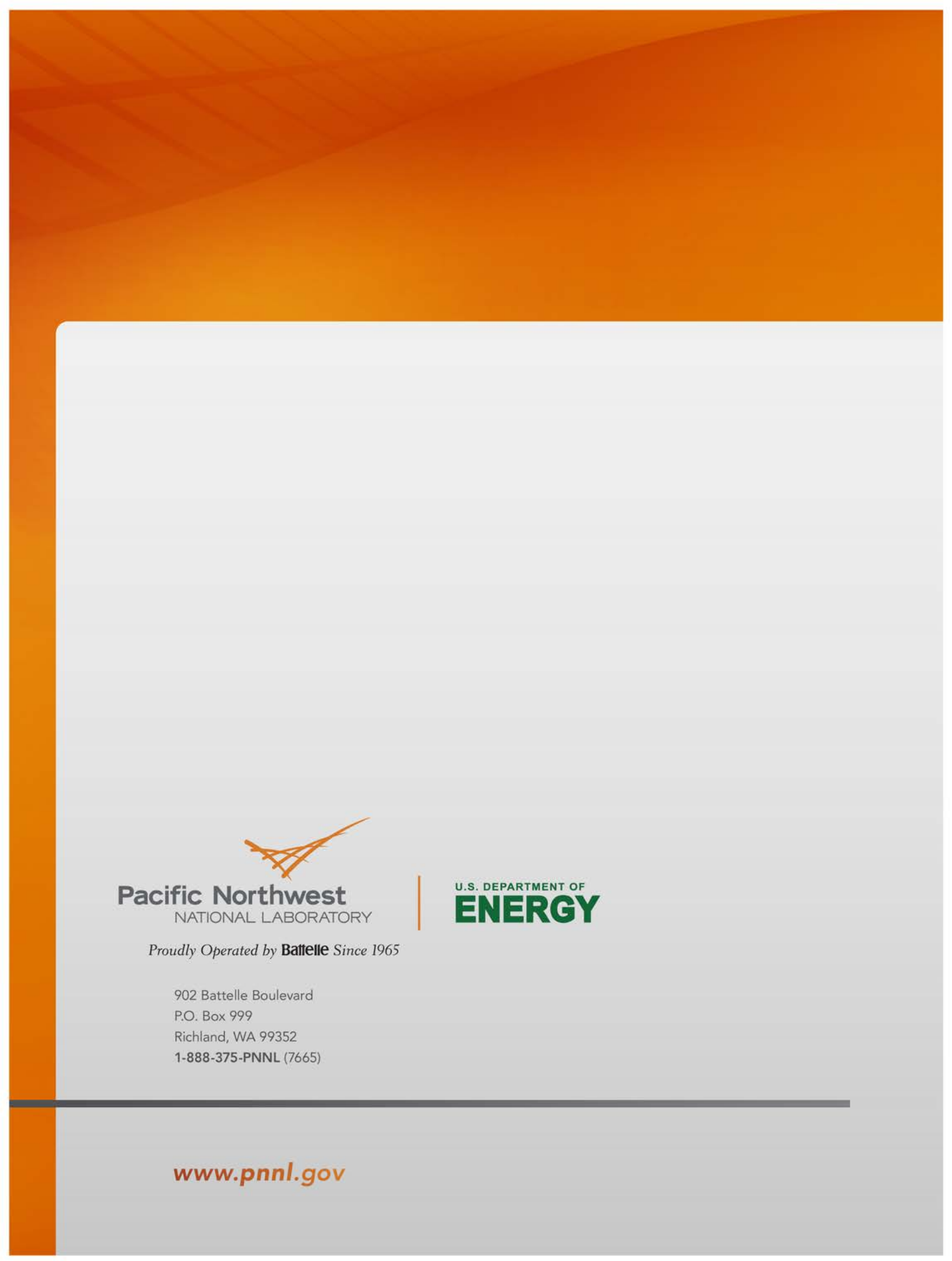

